\title{
Analysis of long-term outcomes after surgery in patients with severe blepharoptosis
}

\section{Soon Il Ka, Sung-Eun Kim, Dae Hwan Park}

Department of Plastic and Reconstructive Surgery, College of Medicine, Catholic University of Daegu, Daegu, Korea
Background Blepharoptosis is the drooping of the margin of the upper eyelid, which narrows the palpebral fissure and makes it difficult to open the eye. Various surgical methods are used to correct blepharoptosis and have been investigated in different studies. After surgery, blepharoptosis can relapse over time, which affects a patient's satisfaction with the operation. However, few studies have investigated the long-term outcomes of patients after blepharoptosis surgery.

Methods From 1991 to 2013, 325 patients (480 eyelids) underwent frontalis muscle transfer or Müller-aponeurosis composite flap advancement in our clinic. We analyzed 12 patients ( 13 eyelids) with severe ptosis who had been followed-up for more than 5 years. Six patients underwent frontalis muscle transfer for the correction of seven eyelids, while Müller-aponeurosis composite flap advancement was performed on six patients (six eyelids). The marginal reflex distance (MRD1), area of corneal exposure (ACE), and height of the eyebrow were used to analyze the objective outcomes, and the Glasgow Benefit Inventory questionnaire was used for the analysis of subjective patient satisfaction.

Results There were no significant differences in the MRD1, ACE, and eyebrow height between the two methods used to correct ptosis. However, over the long-term ( $>5$ years), the MRD1, ACE, and eyebrow height were better maintained in patients who underwent Müller-aponeurosis composite flap advancement than in patients who received frontalis muscle transfer.

Conclusions Both surgeries were effective for blepharoptosis correction. However, Müller-aponeurosis composite flap advancement was better for long-term maintenance after surgery than frontalis muscle transfer.

Keywords Blepharoptosis / Blepharoplasty / Frontalis transfer

\section{INTRODUCTION}

Blepharoptosis involves narrowing of the palpebral fissure, which

Received: Dec 3, 2018 Revised: Dec 25, 2018 Accepted: Dec 27, 2018 Correspondence: Dae Hwan Park Department of Plastic and Reconstructive Surgery, College of Medicine, Catholic University of Daegu, 33 Duryugongwon-ro 17-gil, Nam-gu, Daegu 42472, Korea Tel: +82-53-650-4578, Fax: +82-53-650-4584, E-mail: dhpark@cu.ac.kr Copyright @ 2019 The Korean Society for Aesthetic Plastic Surgery. This is an Open Access article distributed under the terms of the Creative Commons Attribution Non-Commercial License (http://creativecommons.org/licenses/by-nc/4.0/) which permits unrestricted non-commercial use, distribution, and reproduction in any medium, provided the original work is properly cited. www.e-aaps.org makes it difficult to open the eye. Various classifications of blepharoptosis have been proposed. For example, Beard [1] classified blepharoptosis as congenital, acquired, pseudo, or neurogenic. The severity of blepharoptosis can be classified as mild, moderate, or severe [1,2]. Frueh [3] proposed a classification system based on the causative mechanism of blepharoptosis: muscular, fascial, mechanical, neurogenic, and pseudoptosis. The variety in the methods of classifying blepharoptosis is accompanied by a diverse range of surgical treatments that have been used for decades, in addition to which new methods of surgery are being developed.

Blepharoptosis can recur after surgery, thereby affecting a patient's satisfaction and quality of life. Therefore, the long-term results after surgery for blepharoptosis are a very important factor to 
consider when choosing the type of surgical treatment. Previous studies have discussed the results of different types of blepharoptosis surgery, but there are few long-term follow-up studies on patients after surgery. Therefore, in this study, patients with severe blepharoptosis who had been followed up for more than 5 years were divided into two groups based on the type of surgery they received. The long-term results after surgery were then analyzed in both groups.

\section{METHODS}

\section{Patients}

From 1991 to 2013, 325 patients (with a total of 480 eyelids) underwent frontalis muscle transfer or Müller-aponeurosis composite flap advancement at our clinic. In all, 12 patients (with a total of 13 eyelids) with severe blepharoptosis were followed up for more than 5 years (average follow-up period, 7.96 years). Six of those patients (7 eyelids) underwent frontalis muscle transfer and six patients (6 eyelids) underwent Müller-aponeurosis composite flap advancement (Table 1).

Table 1. Patient demographics

\begin{tabular}{|c|c|c|c|c|c|}
\hline No. & Sex & Age (yr) & Diagnosis & Operation & Follow-up period \\
\hline 1 & Male & 49 & Blepharoptosis (Lt) & Frontalis transfer (Lt) & 13 yr 5 mo \\
\hline 2 & Male & 59 & Blepharoptosis (Lt) & Frontalis transfer $(\mathrm{Lt})$ & $5 \mathrm{yr} 1 \mathrm{mo}$ \\
\hline 3 & Male & 63 & Blepharoptosis (Rt) & Frontalis transfer (Rt) & 10 yr 7 mo \\
\hline 4 & Male & 21 & Blepharoptosis (Rt) & Frontalis transfer (Rt) & $5 \mathrm{yr} 3 \mathrm{mo}$ \\
\hline 5 & Female & 23 & Blepharoptosis (Lt) & Frontalis transfer $(\mathrm{Lt})$ & 5 yr 9 mo \\
\hline 6 & Male & 41 & Blepharoptosis (Both) & Frontalis transfer (Both) & $7 \mathrm{yr} 11 \mathrm{mo}$ \\
\hline 7 & Female & 7 & Blepharoptosis (Lt) & M-A composite flap advancement (Lt) & $5 \mathrm{yr} 1 \mathrm{mo}$ \\
\hline 8 & Male & 21 & Blepharoptosis (Lt) & M-A composite flap advancement (Lt) & 5 yr 3 mo \\
\hline 9 & Female & 46 & Blepharoptosis (Rt) & M-A composite flap advancement (Rt) & 13 yr 3 mo \\
\hline 10 & Female & 54 & Blepharoptosis (Rt) & M-A composite flap advancement (Rt) & $5 \mathrm{yr} 10 \mathrm{mo}$ \\
\hline 11 & Female & 18 & Blepharoptosis (Lt) & M-A composite flap advancement (Lt) & $6 \mathrm{yr} 8 \mathrm{mo}$ \\
\hline 12 & Female & 36 & Blepharoptosis (Lt) & M-A composite flap advancement (Lt) & 11 yr 6 mo \\
\hline
\end{tabular}

Lt, left; Rt, right; M-A, Müller-aponeurosis composite flap advancement.
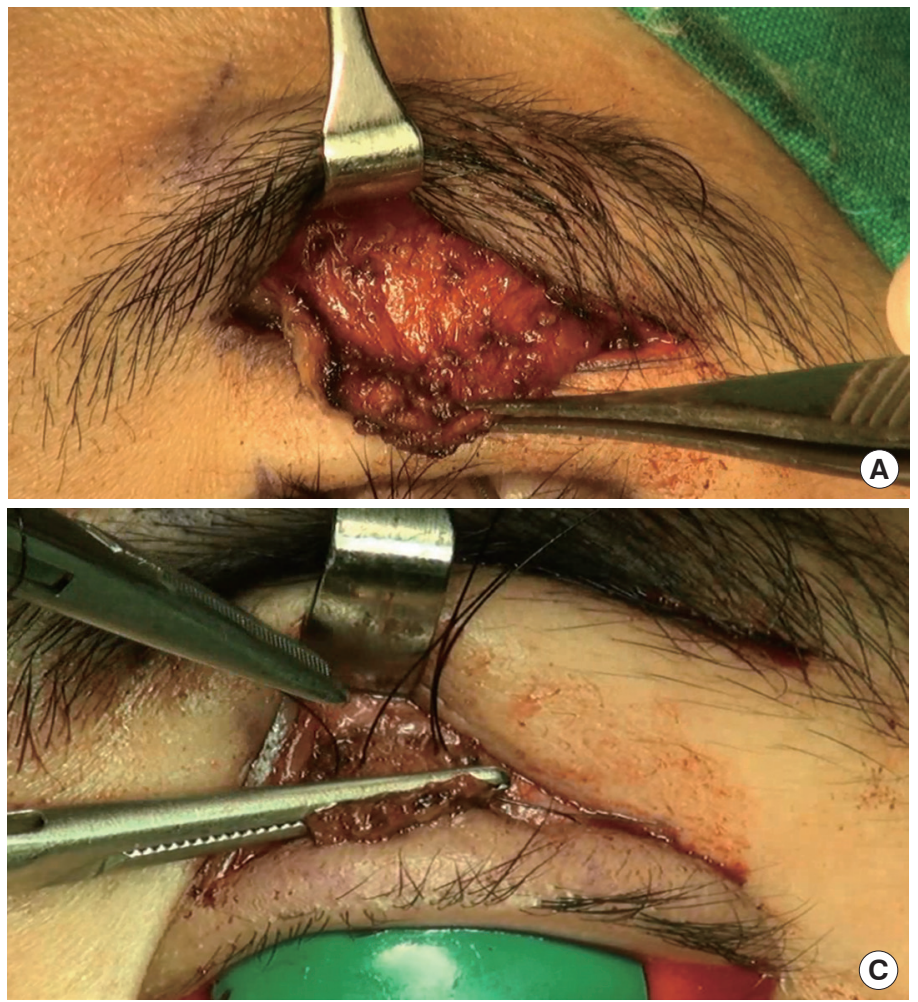

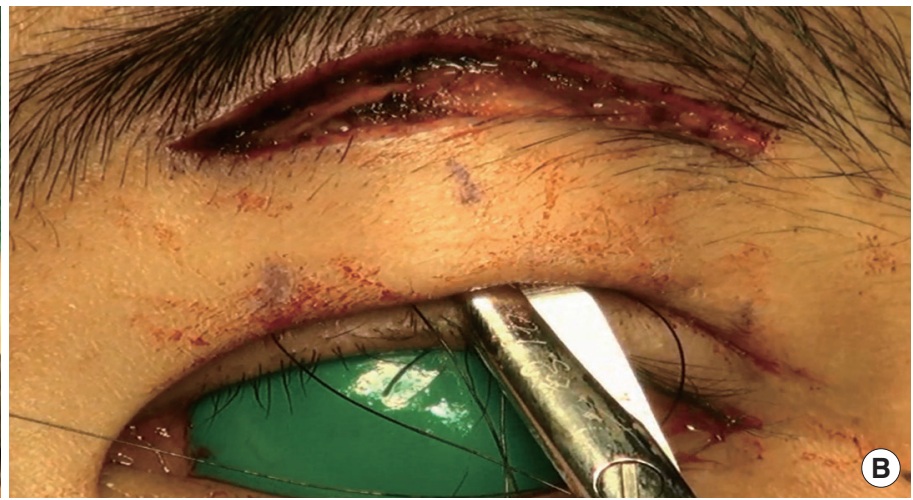

Fig. 1. Surgical procedures of frontalis muscle transfer. (A) Exposure of the frontalis muscle and elevation of the L-shaped frontal muscle flap. (B) Tunneling from the supratarsal incision line to the inferior margin of the eyebrow. (C) Fixation of the frontalis muscle flap $2 \mathrm{~mm}$ below the upper margin of the tarsal plate with 5-0 polydioxanone sutures. 


\section{Surgical methods \\ Frontalis muscle transfer}

Along the planned incision line, $1 \%$ lidocaine was infiltrated with 1:200,000 epinephrine. The skin was cut along the inferior margin of the eyebrow and the supratarsal region with a No. 15 blade. Dissection was performed approximately 2.5 to $3.0 \mathrm{~cm}$ above the superior margin of the eyebrow. A cut was made $2 \mathrm{~cm}$ horizontally and $1 \mathrm{~cm}$ vertically to expose the frontal muscle. The L-shaped frontal muscle flap was elevated, at which time soft tissue was also included for thickness. A tunnel was made from the inferior eyebrow margin to the supratarsal incision, passing the Metzenbaum scissors between the orbital septum and the orbicularis oculi. The smallest possible tunnel was made to avoid entropion. After passing the frontalis muscle flap through the tunnel beneath the orbital septum $2 \mathrm{~mm}$ below the upper margin of the tarsus, the frontalis muscle flap was fixed $2 \mathrm{~mm}$ below the upper margin of the tarsal plate with 5-0 polydioxanone (PDS) sutures, using 2 to 3 points. Overcorrection was performed approximately $1 \mathrm{~mm}$ above the normal eye during the operation. The overcorrected position was adjusted to match the upper margin of the iris and the margin of the upper eyelid. The knot was tightened at least 5 times to prevent loosening. The skin was closed with nylon 7-0 (Fig. 1).

\section{Müller-aponeurosis composite flap advancement}

Along the planned incision line, 1\% lidocaine was infiltrated with 1:200,000 epinephrine. The skin and the orbicularis oculi muscle were cut. The orbital septum was slightly excised and the orbital fat was exposed. The orbital fat was separated from the levator aponeurosis. The advancement point was marked on the aponeurosis. In this study, the amount of advancement was approximately 3 to $3.5 \mathrm{~mm}$ to correct $1 \mathrm{~mm}$ of blepharoptosis, and overcorrection was not performed. After excising the pretarsal soft tissue, $1 \%$ lidocaine mixed with 1:100,000 epinephrine was infiltrated into the conjunctiva to facilitate an easy dissection between the Müller muscle and the conjunctiva. Using blunt scissors, the conjunctiva and the Müller muscle were separated approximately $2 \mathrm{~mm}$ above the upper margin of the tarsal plate. A mosquito clamp was inserted along the dissected plane. The Müller-aponeurosis composite flap was cut from the superior portion of the tarsus and dissected from the conjunctiva. The Müller-aponeurosis composite flap was then advanced and fixed 2 to $3 \mathrm{~mm}$ below the upper margin of the tarsal plate with 5-0 PDS sutures, using 2 points. The remnant flap was removed. The tarsal Müller-aponeurosis composite flap suture was reinforced, and the skin was closed with nylon 7-0 sutures (Fig. 2).
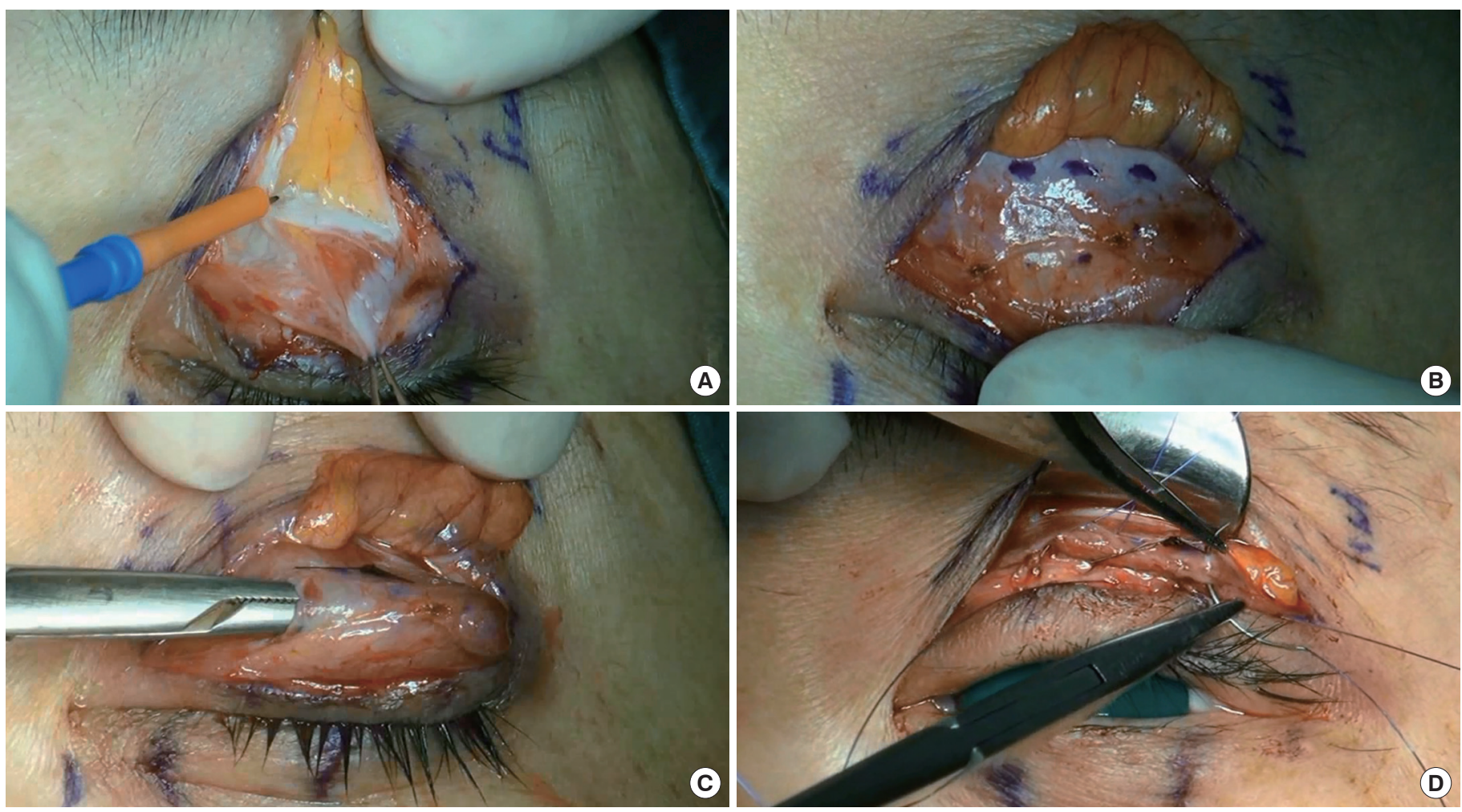

Fig. 2. Surgical procedures of Müller-aponeurosis composite flap advancement. (A) Separation of orbital fat from the levator aponeurosis. (B) Design of the advancement point on the aponeurosis. The amount of advancement was about 3-3.5 mm to correct $1 \mathrm{~mm}$ of blepharoptosis. (C) Insertion of a straight mosquito clamp along the dissected plane. (D) Fixation of the Müller-aponeurosis composite flap 2-3 mm below the upper margin of the tarsal plate with 5-0 polydioxanone sutures. 


\section{Assessment}

To analyze the results objectively, patients' marginal reflex distance (MRD1), area of corneal exposure (ACE), and eyebrow height were measured. Measurements were taken preoperatively and postoperatively, after swelling had diminished (approximately 1 month after surgery) and at the last follow-up appointment ( $>5$ years after surgery). Changes were analyzed quantitatively by averaging the differences between each patient. Adobe Photoshop CS3 software and a Java-based image processing program (ImageJ 1.40; National Institute of Health, Bethesda, MD, USA) were used to calculate each measurement parameter. To reduce error, the diameter of each patient's cornea was measured and corrected to an average corneal diameter of $11.3 \mathrm{~mm}$, which is the average Korean corneal diameter [4]. The Mann-Whitney U-test was used to compare the degree to which parameters increased or decreased. The data were analyzed using SPSS version 25.0 (IBM Corp., Armonk, NY, USA). P-values $<0.05$ were considered to indicate statistical significance. Patient satisfaction was measured using the Glasgow Benefit Inventory (GBI) questionnaire, which evaluated 18 factors [5].

\section{RESULTS}

This study examined six patients (7 eyelids) who had undergone frontalis muscle transfer. The average preoperative MRD1 of these patients was $-1.41 \mathrm{~mm}$, which increased by $4.39 \mathrm{~mm}$ to become $2.98 \mathrm{~mm}$, while the average MRD1 at more than 5 years post-surgery decreased by $0.59 \mathrm{~mm}$ to become $2.39 \mathrm{~mm}$. The average preoperative MRD1 of the six patients (6 eyelids) who underwent Müller-aponeurosis composite flap advancement was $-1.1 \mathrm{~mm}$; this value increased by $4.01 \mathrm{~mm}$ to become $2.91 \mathrm{~mm}$, while the average MRD1 at more than 5 years post-surgery decreased by 0.26 $\mathrm{mm}$ to become $2.65 \mathrm{~mm}$ (Table 2).

The average preoperative ACE of patients who underwent frontalis muscle transfer was $27.4 \%$; on average, it increased by $32.1 \%$ to $59.5 \%$, while the average ACE at more than 5 years post-surgery decreased by $11.8 \%$ to $47.7 \%$. In patients who underwent Müller-aponeurosis composite flap advancement, the average preoperative ACE was $31.2 \%$; on average, it increased by $30.2 \%$ to $61.4 \%$, while the average ACE decreased by $6.9 \%$ to $54.5 \%$ at more than 5 years postsurgery (Table 3).

The average eyebrow height of patients who underwent frontalis muscle transfer had increased by $18.0 \mathrm{~mm}$ at more than 5 years post-surgery. The average eyebrow height of patients who underwent Müller-aponeurosis composite flap advancement had increased by $10.9 \mathrm{~mm}$ at more than 5 years post-surgery (Table 4 ).

Statistical analysis was used to compare the increases and de-

Table 2. Average improvements in MRD1 post-surgery $(n=6)$

\begin{tabular}{lccc}
\hline & $\sim 1$ Month postoperatively & After 5 years & Decrease \\
\hline Frontalis muscle transfer (7 eyelids) & $2.98 \pm 0.25$ & $2.39 \pm 0.26$ & $0.59 \pm 0.38$ \\
Müller-aponeurosis composite flap advancement & $2.91 \pm 0.24$ & $2.65 \pm 0.21$ & $0.26 \pm 0.21$ \\
(6 eyelids) & & & 0.045
\end{tabular}

Values are presented as average $\pm S D$. All unit of data is millimeter.

MRD1, marginal reflex distance.

Table 3. Average improvements in ACE after surgery ( $n=6$ )

\begin{tabular}{lccc}
\hline & $\sim 1$ Month postoperatively & After 5 years & Decrease \\
\hline Frontalis muscle transfer (7 eyelids) & $59.5 \pm 7.76$ & $47.7 \pm 8.26$ & $11.8 \pm 5.39$ \\
Müller-aponeurosis composite flap advancement & $61.4 \pm 6.03$ & $54.5 \pm 7.98$ & $6.9 \pm 5.07$
\end{tabular}

Values are presented as average $\pm S D$. All unit of data is percentage.

ACE, area of corneal exposure.

Table 4. Average changes in eyebrow height after surgery $(n=6)$

\begin{tabular}{lcccc}
\hline & \multicolumn{3}{c}{ Change in eyebrow height after 5 years } \\
\cline { 2 - 4 } & H1 & H2 & H3 & Average \\
\hline Frontalis muscle transfer (7 eyelids) & $18.4 \pm 5.22$ & $17.4 \pm 5.34$ & $18.3 \pm 5.47$ & $18.0 \pm 4.60$ \\
$\begin{array}{l}\text { Müller-aponeurosis composite flap advancement } \\
\text { (6 eyelids) }\end{array}$ & $11.1 \pm 4.03$ & $10.7 \pm 4.15$ & $11.1 \pm 4.09$ & $10.9 \pm 2.51$ \\
\hline
\end{tabular}

Values are presented as average \pm SD. All unit of data is millimeter.

$\mathrm{H} 1$, measured from the lateral canthus to the lateral upper margin of the eyebrow; $\mathrm{H} 2$, measured from the center of the pupil to the center of the upper margin of the eyebrow; $\mathrm{H} 3$, measured from the medial canthus to the medial upper margin of the eyebrow. 
creases in these values according to the surgical method at more than 5 years post-surgery. A significant difference according to the surgical method was found in the decrease of the MRD1 value after 5 years $(\mathrm{P}=0.045)$. Furthermore, the eyebrow height change at more than 5 years showed a significant difference $(\mathrm{P}=0.015)$. However, no significant differences in ACE values were observed $(\mathrm{P}=0.199)$.

The GBI questionnaire was used to examine patient satisfaction post-surgery. The GBI scores of patients who underwent frontalis muscle transfer and Müller-aponeurosis composite flap advancement were 26.12 and 32.24 , respectively.

\section{DISCUSSION}

In a study by Park et al. [6], 214 patients (306 eyelids) received different treatments to correct severe blepharoptosis; 143 patients (217 eyelids) underwent frontalis muscle transfer and 71 patients (89 eyelids) underwent Müller-aponeurosis composite flap advancement. The postoperative results were analyzed in terms of the MRD1, ACE, and height of the eyebrows. No significant difference was found between the two groups, and both surgical methods were demonstrated to be effective methods for correcting severe blepharoptosis [6]. Other studies have reported the Müller-aponeurosis composite flap advancement procedure has the advantage of preventing complications that can occur with frontalis muscle transfer $[7,8]$. In these studies, both surgical procedures were effective in correcting blepharoptosis.

In this study, we analyzed long-term results in patients who underwent frontalis muscle transfer or Müller-aponeurosis composite flap advancement. Mokhtarzadeh and Bradley [9] investigated the outcomes of 47 patients with congenital blepharoptosis after an average follow-up of 3.3 years. Watanabe et al. [10] investigated changes in tear volume in 27 patients ( 43 eyelids) for an average of 6 months. Innocenti et al. [11] examined long-term results in 20 patients (40 eyelids) who underwent external levator muscle complex advancement; the researchers confirmed that 3 years after surgery, the MRD1 had been maintained successfully in $92.5 \%$ of patients. In that study, most of the patients who did not maintain their MRD1 after surgery were elderly patients with severe blepharoptosis. However, their study did not find that the MRD1 decreased after 3 years [11]. Other studies have also analyzed the long-term results of blepharoptosis surgery, although few studies have followed up patients for more than 3 years.

The preoperative degree of blepharoptosis affects the postoperative results. In addition, the MRD1 is often not maintained in older patients or in patients with severe blepharoptosis [11]. Therefore, to make an accurate comparison, this study examined only patients with severe blepharoptosis. When the long-term outcomes of both operations were compared, the patients who underwent frontalis muscle transfer showed more changes in the MRD1, ACE, and eyebrow height. After more than 5 years, the MRD1 and ACE decreased significantly, and there was a greater increase in the height of the eyebrows in patients who underwent frontalis muscle transfer than in patients who underwent Müller-aponeurosis composite flap advancement.

Skin laxity occurs a long time after surgery, and is inevitably accompanied by blepharoptosis. However, Müller-aponeurosis composite flap advancement has been proven to be more effective than frontalis muscle transfer in maintaining the surgical outcomes in terms of the decrease in MRD1 and ACE and the increase in eyebrow height. The different results associated with the different procedures are thought to be due to the lack of hard fixation of the frontalis muscle to the tarsal plate or to the loosening of the fixation with time in patients who undergo frontal transfer surgery.

Smith et al. [5] investigated 50 patients with blepharoptosis and found that the average GBI score was 24.89. In contrast, the satisfaction of the patients in the present study was found to be high for both surgical techniques, although patient satisfaction was higher for the Müller-aponeurosis composite flap advancement procedure than for frontalis muscle transfer. Patients may have been more satisfied with Müller-aponeurosis composite flap advancement because the results were maintained, which is generally associated with patient satisfaction.

In this study, we examined the long-term results after frontalis muscle transfer and Müller-aponeurosis composite flap advancement. Although there was no statistical significance in the decrease of ACE, the average decrease itself was less in patients who underwent Müller-aponeurosis composite flap advancement. The decrease of the MRD1 value and eyebrow height change after 5 years showed significant differences. In this respect, we consider that Müller-aponeurosis composite flap advancement was more effective in maintaining the surgical results in terms of measurements (objective factors) and patient satisfaction (a subjective factor). In addition, the average follow-up period of 7.96 years in this study is longer than the follow-up in other studies. Determining the longterm results and outcomes of blepharoptosis surgery is very important because they affect patient satisfaction. In the future, the results of this study can be used as a guideline when selecting blepharoptosis surgery.

\section{CONFLICT OF INTEREST}

No potential conflict of interest relevant to this article was reported.

\section{ETHICAL APPROVAL}

The study was performed in accordance with the principles of the Declaration of Helsinki. 


\section{PATIENT CONSENT}

The patients provided written informed consent for the publication and the use of their images.

\section{ORCID}

Soon Il Ka (https://orcid.org/0000-0001-5798-5179)

Sung-Eun Kim (https://orcid.org/0000-0002-3413-7094)

Dae Hwan Park (https://orcid.org/0000-0001-9671-6510)

\section{REFERENCES}

1. Beard C. Ptosis. St. Louis: Mosby;1981.

2. Callahan M, Beard C. Beard's ptosis. 4th ed. Birmingham: Aesculapius Publishing Co.;1990.

3. Frueh BR. The mechanistic classification of ptosis. Ophthalmology 1980;87:1019-21.

4. Bae TH, Kim JC, Kim WS, et al. A photogrammetic study of the eyes in Korean youths. J Korean Soc Plast Reconstr Surg 2007;34:37-43.
5. Smith HB, Jyothi SB, Mahroo OA, et al. Patient-reported benefit from oculoplastic surgery. Eye (Lond) 2012;26:1418-23.

6. Park DD, Ramadhan A, Han DG, et al. Comparison of blepharoptosis correction using Müller-aponeurosis composite flap advancement and frontalis muscle transfer. Plast Reconstr Surg Glob Open 2014;2:e200.

7. Park DH, Choi WS, Yoon SH, et al. Comparison of levator resection and frontalis muscle transfer in the treatment of severe blepharoptosis. Ann Plast Surg 2007;59:388-92.

8. Beyer-Machule CK. Congenital ptosis and complications of ptosis surgery. Plast Reconstr Surg 1988;81:789-99.

9. Mokhtarzadeh A, Bradley EA. Safety and long-term outcomes of congenital ptosis surgery: a population-based study. J Pediatr Ophthalmol Strabismus 2016;53:212-7.

10. Watanabe A, Selva D, Kakizaki H, et al. Long-term tear volume changes after blepharoptosis surgery and blepharoplasty. Invest Ophthalmol Vis Sci 2014;56:54-8.

11. Innocenti A, Mori F, Melita D, et al. Evaluation of long-term outcomes of correction of severe blepharoptosis with advancement of external levator muscle complex: descriptive statistical analysis of the results. In Vivo 2017;31:111-5. 